\title{
Compounds Identification in Agar Wood Soaking Water by Using GC-MS
}

\author{
Veronica Alexander Jok, Mohamad Arif Fadhli Zainudin, Nurhaslina Che Radzi, and Ku Halim Ku \\ Hamid
}

\begin{abstract}
Soaking process in agar wood oil extraction is essential to enhance the extraction process while increasing the oil yield. However, soaking water in agar wood extraction process normally drown out and not being used due to its unpleasant smell. During soaking process, some compounds were leached out because of the pore opening. Therefore, soaking water from agar wood may contain important chemicals which are useful for other application. Solvent separation using hexane was chosen to separate the compounds from soaking water to identify the potential compounds. In this work, Tributyrin was found to be the main compounds in hexane extract from the soaking process. 3 ratios of solvent and samples were chosen. From the results, the solvent to samples ratio 1:1 found to be the best for the separation. As conclusion, the soaking water of agar wood contains Tributyrin which is potentially used in cancer treatment and food processing industry.
\end{abstract}

Index Terms-Agar wood, soaking water, GC-MS, solvent extraction.

\section{INTRODUCTION}

In the process of extracting agar wood oil, the chips were soaked into solvent to enhance the pore opening, therefore enhance the oil yield. Previous studies on different solvents for soaking process show different effects towards the oil yield. Current practice in the industry is mainly using tap water while only the more advance manufacturers are using chemicals to soak. Normally, the soaked water were discharged to the drain after soaking process. It is brownish in colour and has unpleasant odor. Our previous works shows that the soaked water is acidic too.

According to the Bayram et al. [1], mass transfer happens between the soy cells and its soaking water. Therefore, some compounds are released during the soaking process. Some important compound could be released during this steps. On the other hand, there is no study on the chemical composition in the agar wood soaked water. Agar wood soaked water may content some essential component that released during soaking process. Pore opens during the process and allows the compounds to escape from the cells [2].

Since the water used for soaking is in large quantity, it

Manuscript received July 12, 2015; revised December 25, 2015. This work was supported in part by the Universiti Teknologi MARA (UiTM) under Zamalah Grant.

The authors are with the Faculty of Chemical Engineering, Universiti Teknologi MARA (UiTM) Shah Alam, Malaysia (e-mail: veronica.alexjok@gmail.com, nurhaslina483@ salam.uitm.edu.my). might be useful to be use or to be further processed or recycled in other application. However, this only can be achieved provided that the soaking water contains useful compounds. In this work, the compounds in agar wood soaking water to be identified. It must be extracted by using hexane first before examined by using GC-MS analysis. The estimated on the amount of compounds in the hexane extract were suggested too.

\section{MATERIALS AND METHOD}

The agarwood hard wood were bought from a plantation in Jengka, Pahang. The wood need to be chipped into small pieces by using chipper. 1 batch of a process requires $25 \mathrm{~kg}$ of the chips. For 1 batch, $25 \mathrm{~kg}$ of agar wood chips were dried under the sun for 4 hours, followed by soaked in $125 \mathrm{~kg}$ of tap water. The agarwood chips were fully immersed into the tap water and left to soaked in covered barrels for 7, 14, 21 and 28 days. The soaking water samples were collected and stored in the fridge at $-4{ }^{\circ} \mathrm{C}$ until the samples are prepared for analysis.

Gas chromatography - mass spectrometer (GC-MS) analysis were conducted on all the samples separated from the soaked water. The samples need to be prepared by using solvent extraction method. Simple solvent extraction using hexane (analysis grade) conducted on the separator funnel. Different ratio of solvent and samples were used, which are 1:1, 1:2 and 2:1. Hexane was added to the samples and the mixtures were shook vigorously in 100 counts. The mixtures were left to separate for 1 hours. The separated samples were collected into samples bottle and sent for analysis.

The GC-MS examinations were performed through Varian 450 gas chromatograph with appended Varian 240 mass spectrometer. This apparatus was outfitted with DB-1 narrow section $(30 \mathrm{~m} \times 0.25 \mathrm{~mm} \times$ film thickness $0.25 \mu \mathrm{m})$. Injector temperature was situated at $230{ }^{\circ} \mathrm{C}$ and oven temperature was programmed somewhere around 50 and $230{ }^{\circ} \mathrm{C}$ at a rate of 3 ${ }^{\circ} \mathrm{C} / \mathrm{min}$. Infusion volume was $3 \mu \mathrm{l}$ with part proportion 20:1. Helium was utilized as transporter gas.

The estimated percentage of compounds in the extracts were calculated from the percentage suggested by GC-MS results.

\section{RESULT AND DISCUSSION}

Total compounds detected by GC-MS instruments are 6 in total as listed in Table I. These compounds were detected in comparison to 40 other compounds which are presents in agarwood oils and extracts from the literatures. Based on the 
result, it is found that all of the samples contain Tributyrin. This shows that Tributyrin is the main compounds found in the hexane extracts separated from the soaking water.

Tributyrin formula is $\mathrm{C}_{15} \mathrm{H}_{26} \mathrm{O}_{6}$ and belongs to triglyceride group. The chemical structure shows in Fig. 1. Tributyrin is one of the compounds that can be used as alternative medicine in cancer treatment. Latest research on Tributyrin is on the colon cancer [3], [4]. This compound composed of a triglyceride with 3 butyrate glyceryl tributyrates and in liquid state at room temperature which allows it for oral consumption [3], [5].

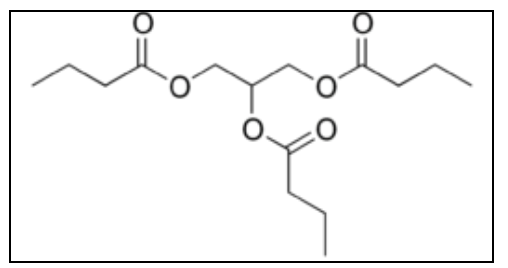

Fig. 1. Chemical structure of Tributyrin.

Some phytochemical compounds were classified by Mehta (2010) [6] in Table II. Even though Tributyrin is not listed, previous researches shows promising application in cancer treatment. Another application of Tributyrin is in the cheese lipolysis. As conclusion, the soaking water of agar wood contains important compounds for both medical and food process.

Other than that, Tributyrin also found to be an enhancer of drug intake for anticancer drugs by improving the characteristic of liposomes [7]. It has dual function during the consumption of anticancer drugs for colon cancer, which are to solute and enhance the poorly water-soluble anticancer drugs into the system. [4].With the addition of Tributyrin emulsion into the system has improve the anticancer activity of the drugs which cause by the solubilization capacity of the Tributyrin.

On the other hand, recent study on Tributyrin also prove that it can reduce the cholesterol level. Makata et al. [8] study the effect of oral consumption of Tributyrin toward the level of plasma triglyceride, total cholesterol and low-density lipoprotein cholesterol in rat. The clinical research shows that Tributyrin is important for health science area. The Tributyrin from agarwood could be one of the important green source for this purpose.

Fig. 2 shows the Tributyrin content in the hexane extracts from agar wood soaking water samples. From the figure, Tributyrin content increase as the soaking time increase. The graph pattern also shows that solvent to sample ratio at 1:1 gave the highest Tributyrin content in all samples except for Day 21. In our previous work, it was found that the optimum time for soaking agar wood chips in water is 14 days [9]. These results also supported by the previous work by Raina [10], on the optimum soaking time in order to produce high quality agarwood oil. Hence, this work is in line with other researches. Therefore based on the findings, the best solvent to samples ratio for recovering Tributyrin from the soaking water is $1: 1$.

Other compounds present in the hexane extracts are $\mathrm{N}$-[4-(4-Chlorophenyl) isothiazol-5-yl) -1- methylpiperidin 2- im, Hydroxylupanine, Octadecanoic acid methyl ester,
9-Dodecenoic acid methyl ester, (E)-, and 4-Heptanol. From the table, Octadecanoic acid, methyl ester present in all samples except at Day 7 (1:2). This shows that the soaking water is acidic in nature. These findings are corresponding to our previous works on the $\mathrm{pH}$ profiles during soaking process [11]. This is similar to the condition of soy-bulgur soaking time study by Bayram et al. [1]. To the best of our knowledge, there is no study on the soaking time effect towards acidity of soak water for agarwood.

TABLE I: COMPOUNDS IDENTIFIED FROM GC-MS ANALYSIS OF AGAR WOOD SOAKED WATER

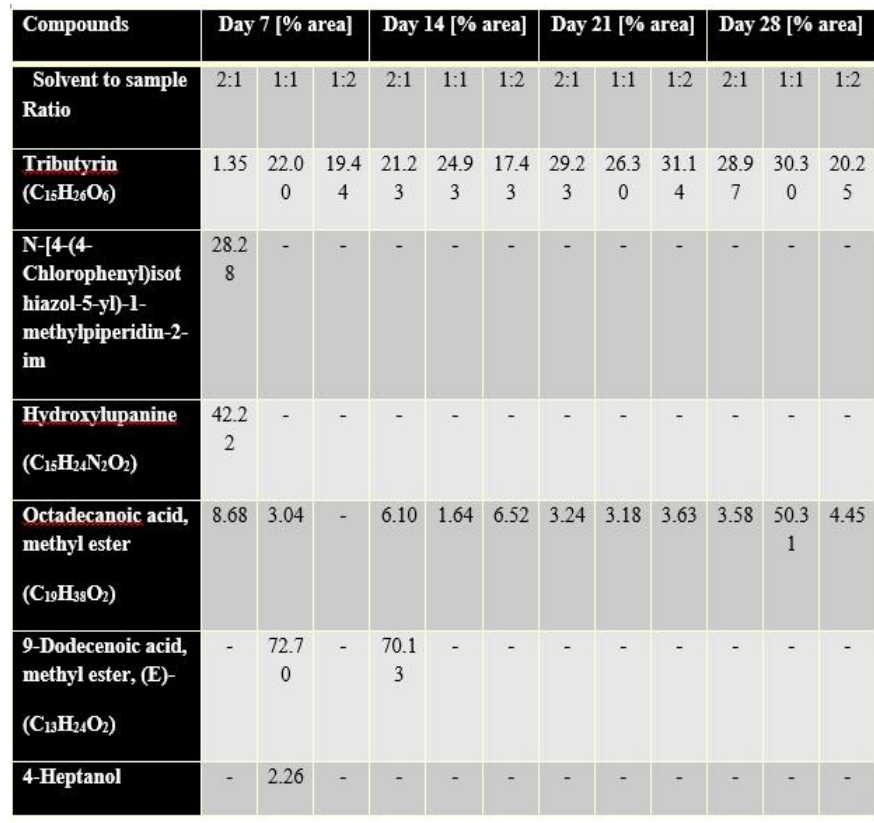

TABLE II: ACTIVITY OF DIFFERENT PHYTOCHEMICALS Constituents (phytochemicals) Activity

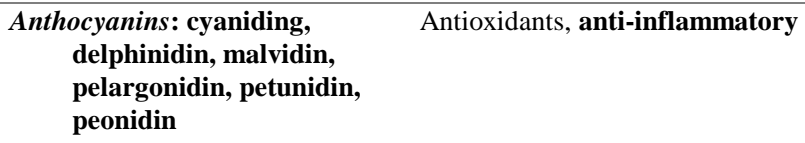

Anthocyanins: cyaniding, Antioxidants, anti-inflammatory delphinidin, malvidin, pelargonidin, petunidin, peonidin

\section{Flavanols: (+)-catechin} (+polymers: condensed tannins), (-)-epicatechin, proanthocyanidins

Astringent, anti-inflammatory, styptic, antiviral

Flavonoids: hyperoside (hyperin), quercetin, isoquercetin, rutin, methyhespericin, iso-quercitrin, quercitrin, I-3/II-8-biapigenin, kaempferol, myricetin
Capillary-strengthening, diuretic, antidiarrheal, anti-inflammatory, arteries, sedative, tumor inhibition, antitumor

\section{Isoflavones: genistein, genistin, Antiosteoperosis, phytoestrogen, daidzein, daidzin, anti-colon cancer puerarin}

Lignans: podophyllotoxin, $\alpha-\quad$ Anti-cancer, antioxidants
and $\beta$-peltatin

Sesquiterpenes: caryophyllene, Anti-cancer humulene, farnesol, artemisinin

Diterpenes: cafestol, kahweol, Anti-inflammatory, anti-hypertensive cembrene, taxadiene

Phytosterols: $\boldsymbol{\beta}$-sitosterol Anti-cancer, benign prostatic hypertrophy 
Acidic condition during the soaking process enhances the pore openings by corroding the external wall of plant tissue, while the water mass transferring into the cells creates a turgid condition. Both external and internal factor caused the compound to secrete to the soaked water environment. That is the time where the compounds escaped from the cells.

The soaking time also affect the quantity of the compounds released to the soaked water. Taking Tributyrin as examples; the longer the soaking time, more Tributyrin were released to the soaked water environment. Over soaking of the plant material can caused the essential components in agarwood wasted to the soak water. This study and Raina's work [10] proven to be rigid evident to this phenomenon. Longer soaking time may increase the yield, but over soaking could give lower yield. Due to this effect, it is not recommended to soak the agarwood chips longer. Optimum time must be identified to avoid the loss of important compounds. In agarwood oil industry, the quality of oil depends on the essential compounds present in the oil. Therefore, the loss of these important compounds may affect the quality of oil.

\section{Tributyrin content in hexane extract from agar wood soaking water}

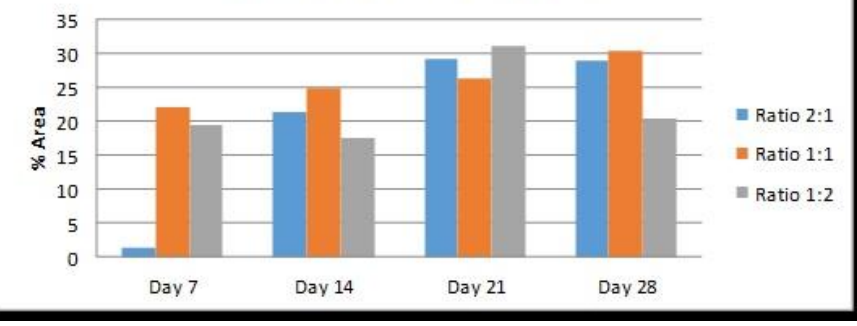

Fig. 2. Tributyrin content in hexane extracts from agarwood soaking water.

\section{CONCLUSION AND RECOMMENDATION}

Tributyrin is the main compounds released during the soaking process of agarwood chips. Other essential compounds reported in other works do not leached out during the process. Tributyrin found to be useful in the treatment of cancer and in food processing. Therefore, a method to recover this compound from the agar wood soaking water is essential because the wood is very expensive. The ratio of solvents has significant effect to the quantity of Tributyrin extracted from the soaked water during the GC-MS samples preparation. The best ratio is $1: 1$. However, other less harmful solvents could be use in future research.

\section{ACKNOWLEDGEMENT}

The authors want to thank Zamalah Grant Scheme for the funding. Authors also want to express special gratitude to Universiti Teknologi MARA, UiTM Shah Alam, specifically to Faculty of Chemical Engineering for allowing the usage of facilities. Many thanks to all who have been directly and indirectly help through the work.

\section{REFERENCES}

[1] M. Bayram, A. Kaya, and M. D. Öner, "Changes in properties of soaking water during production of soy-bulgur," Journal of Food Engineering, vol. 61, pp. 221-230, 2004.
[2] T.-B. Zou, M. Wang, R.-Y. Gan, and W.-H. Ling, "Optimization of ultrasound-assisted extraction of anthocyanins from mulberry, using response surface methodology," International Journal of Molecular Sciences, vol. 12, no. 5, pp. 3006-3017, 2011.

[3] R. Heidor, K. S. Furtado, and J. F. Ortega et al., "The chemopreventive activity of the histone deacetylase inhibitor tributyrin in colon carcinogenesis involves the induction of apoptosis and reduction of DNA damage," Toxicology and Applied Pharmacology, vol. 276, no. 2, pp. 129-135, 2014.

[4] S. N. Kang, S.-S. Hona, M.-K. Lee, and S.-J. Lim, "Dual function of tributyrin emulsion: Solubilization and enhancement of anticancer effect of celecoxib," International Journal of Pharmaceutics, vol. 428 , no. $1-2$, pp. 76-81, 2012

[5] L. Dong, X. Zhong, J. T. He, L.-L. Zhang, K.-W. Bai, W. Xu, T. Wang, and X.-X. Huang, "Supplementation of tributyrin improves the growth and intestinal digestive and barrier functions in intrauterine growth-restricted piglets," Clinical Nutrition, March 2015.

[6] I. S. Mehta, M. Amira, A. J Harvey, and J. M. Bridger, "Rapid chromosome territory relocation by nuclear motor activity in response to serum removal in primary human fibroblasts," Genome Biology, vol. 11, no. 1:R5, 2010.

[7] S. N. Kanga, S.-S. Honga, S.-Y. Kima, H. Ohb, M.-K. Leec, and Soo-Jeong Lima, "Enhancement of liposomal stability and cellular drug uptake by incorporating tributyrin into celecoxib-loaded liposomes," Asian Journal of Pharmaceutical Sciences, vol. 8, no. 2 , pp. 128-133, April 2013.

[8] M. Miyoshi, N. Iizuka, S. Sakai, M. Fujiwara, M. Aoyama-Ishikawa, Noriaki Maeshige, Y. Hamada, M. Takahashi, and M. Usami, "Oral tributyrin prevents endotoxin-induced lipid metabolism disorder," in Proc. 2015 Clinical Nutrition ESPEN, 2015, vol. 10, pp. e83-e88.

[9] V. A. Jok, N. Che Radzi, and K. H. Ku Hamid, "Agarwood oil yield as a result of changes in cell morphology due to soaking process," in Proc. 2015 World Conference on Technology, Innovation and Entrepreneurship, 2015.

[10] R. Verina, "Soaking time optimization of agarwood kemedangan of inoculated agarwood trees on yield and chemical components," Institusi Pertanian Bogor, 2013.

[11] V. A. Jok, N. Che Radzi, and K. H. Ku Hamid, "Effect of soaking on the temperature and $\mathrm{pH}$ profiles in agarwood extraction," International Journal of Latest Research in Science and Technology, vol. 3, no. 6 , pp. 111-113, November-December 2014

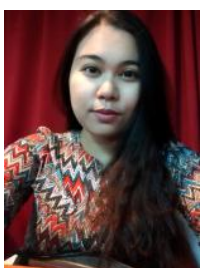

Veronica Alexander Jok is currently pursuing her master in science (chemical engineering) at Universit Teknologi MARA (UiTM) Shah Alam. She is now under Professor Ku Halim Ku Hamid's supervision in completing her master program. Together in supervising she is Madam Nurhaslina Che Radzi. She is currently focusing in agarwood topics related to the process and its yield. She attended 2 local conferences, 1 international conference and has published 1 journa article. Other than that, she also participated in 1 innovation and invention competition where her team won bronze award for the innovation.

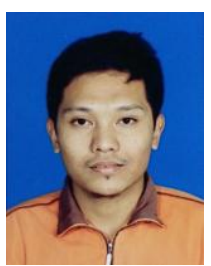

Mohamad Arif Fadhli Zainudin is an undergraduate student for bachelor in chemical engineering at Universiti Teknologi MARA (UiTM) Shah Alam and expected to attend his convocation by May 2016. He is one of the contributor for this paper.

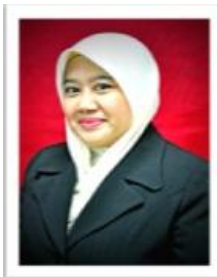

Nurhaslina Che Radzi is a senior lecturer at Faculty of Chemical Engineering, Universiti Teknologi MARA (UiTM) Shah Alam. She has supervised few numbers of master students and published more than 5 papers including journals and conferences. She is also a registered member of Board of Engineers Malaysia. She has co-supervised a number of postgraduate students. As an academician, she has attended numerous conferences and actively 
involved in research projects with other researchers. She also supervised master students to join in the innovation and invention competitions.

Ku Halim Ku Hamid holds the position as a professor and the head of environment and research in the Faculty of Chemical Engineering, Universiti Teknologi MARA (UiTM) Shah Alam. He has supervised more than 30 postgraduate students and published numbers of publication. He is a Malaysian Institute of Chemical Engineers and Malaysian Translation Society member. His working experience as a technical director at Bumi Gemilang Biotechnology (M) Sdn Bhd has provide him the technical knowledge in biotechnology process including agarwood processes. He has more than 5 patented technology and hold a number of research grants to expand his study in numerous area. $\mathrm{He}$ is also actively giving consultancy for projects related to his works. He won a numbers of awards in varies invention and innovation competition, both local and internationally. His research interest are but not limited to catalyst and catalysis, waste treatment - gases, odor, wastewater and solid, energy - bio-fuel and fuel additives, biotechnology new products development for waste treatment, advanced material - new material development, Natural products extraction - tailor to cosmeceutical products, Integrated biological treatment of sewage, Total Biological treatment of leachate and Ammonia stripping of leachate - biological and chemical methods. As an academician, he is also an external examiners for postgraduate students (Universiti Kebangsaan Malaysia, Universiti Sains Malaysia and Universiti Teknologi Malaysia. 